\title{
Neuroengineering tools/applications for bidirectional interfaces, brain-computer interfaces, and neuroprosthetic implants - a review of recent progress
}

\author{
Ryan Mark Rothschild* \\ Department of Physiology, University of Pretoria, Pretoria, South Africa
}

Edited by:

Fabrizio Gelain, University of

Milano-Bicocca, Italy

Reviewed by:

Antonio Novellino, ETT s.r.I., Italy

Axel Blau, The Italian Institute of

Technology, Italy

${ }^{*}$ Correspondence:

Ryan Mark Rothschild, Department of

Physiology, University of Pretoria,

BMW Building, Prinshof Medical

Campus, Dr Savage Road, Pretoria,

South Africa.

e-mail:rm.rothschild@gmail.com
The main focus of this review is to provide a holistic amalgamated overview of the most recent human in vivo techniques for implementing brain-computer interfaces (BCls), bidirectional interfaces, and neuroprosthetics. Neuroengineering is providing new methods for tackling current difficulties; however neuroprosthetics have been studied for decades. Recent progresses are permitting the design of better systems with higher accuracies, repeatability, and system robustness. Bidirectional interfaces integrate recording and the relaying of information from and to the brain for the development of $\mathrm{BCls}$. The concepts of non-invasive and invasive recording of brain activity are introduced. This includes classical and innovative techniques like electroencephalography and near-infrared spectroscopy. Then the problem of gliosis and solutions for (semi-) permanent implant biocompatibility such as innovative implant coatings, materials, and shapes are discussed. Implant power and the transmission of their data through implanted pulse generators and wireless telemetry are taken into account. How sensation can be relayed back to the brain to increase integration of the neuroengineered systems with the body by methods such as micro-stimulation and transcranial magnetic stimulation are then addressed. The neuroprosthetic section discusses some of the various types and how they operate. Visual prosthetics are discussed and the three types, dependant on implant location, are examined. Auditory prosthetics, being cochlear or cortical, are then addressed. Replacement hand and limb prosthetics are then considered. These are followed by sections concentrating on the control of wheelchairs, computers and robotics directly from brain activity as recorded by non-invasive and invasive techniques.

Keywords: neuroengineering, neuroprosthetics, brain-computer interface, brain-machine interface, bidirectional interface, bioelectronics, biocompatibility, multielectrode array

\section{INTRODUCTION}

Damage to the central nervous system (CNS) affects at least 2 million people per year (Rao and Winter, 2009). This may cause physical or sensory disabilities that partially or completely remove functioning. Neuroengineering strives to provide improved quality of life to these people. Even though many of the technologies are in their infantile stage, far from clinical application, they have foreseeable clinical applications in the future. Some of the field specialists include gerontology, rehabilitative medicine, psychiatry, neurology, and clinical research by encompassing subjects such as molecular, cellular, and systems neurobiology (Thakor, 2008; Lin et al., 2010).

Interfaces that can interpret brain activity and use it to control mechanical and computer components have immense potential for applications in various fields. Systems that use this recorded neuronal activity to perform specific tasks are referred to as brainmachine interfaces (BMIs), brain-computer interfaces (BCIs), or neuromotor prostheses (NMP). Neural interface system (NIS) is a term that may be used to refer to any BCI, BMI, or NMP. All NIS rely on sensing neural activity to supply command signals for the direction of computers, machines, and a variety of prosthetic devices. This recorded neuronal activity may be gathered by either non-invasive or invasive techniques (Donoghue et al., 2007; Kayagil et al., 2009; Lee et al., 2009).

There are currently many different technologies used to record and measure activity of the brain. Neuroprosthetic applications for this activity exist, such as the restoration of rudimentary forms of vision and hearing, operation of robotics and computers that allow subjects to communicate and move objects (Lebedev and Nicolelis, 2006; Morillas et al., 2007; Cipriani et al., 2009; Ju et al., 2009; Kayagil et al., 2009; Panetsos et al., 2009; Straley and Heilshorn, 2009). NMP are used to restore lost functional movements in the paralyzed (Song et al., 2007). Their performance is measured by the replication of movement. In communication prosthesis, it is measured by the degree of accuracy in transfer of information (Ryu and Shenoy, 2009).

Multielectrode arrays (MEAs) are one of the main approaches used to record neuronal activity; they are an invasive technique (Chapin, 2004; Smith et al., 2004; Avestruz et al., 2008; Gerven et al., 2009; Kayagil et al., 2009). Recorded information from various non-invasive and invasive techniques is currently being used to re-establish impaired neural function through neuroprosthetic 
devices (Shoval et al., 2009). Advances in biocompatibility technology have increased the lifespan of MEA based NIS to several years as opposed to the months, weeks, or days of their predecessors (Ryu and Shenoy, 2009). The biocompatibility of interactions between the surface molecules of neural implants and neural cells is of specific interest. The fate of implants is often determined by effective integration with the surrounding neural tissue surface. This critical element has been a major roadblock in neuroengineering (Rao and Winter, 2009; Straley and Heilshorn, 2009).

Most of the advances that increase biocompatibility can be attributed to novel materials, coatings, optimized geometries, and electrochemical/mechanical stability (Rao and Winter, 2009; Ryu and Shenoy, 2009; Yaeli et al., 2009). Trace elements in the body, such as silicon which is a common MEA fabrication material, have particulates that are carcinogenic to various cells and organs. These may also initiate inflammation which activates phagocytes and eventually leads to device encapsulation (Frewin et al., 2009). For this reason, specifically biocompatible materials are used to increase device lifespan whilst causing as little tissue damage as possible.

Through bidirectional interfaces, NIS can be used to operate various prosthetic devices. All of which provide different levels of sensation, communication, or movement, dependant on the severity of the disability (Morillas et al., 2007; Panetsos et al., 2009; Ryu and Shenoy, 2009; Konrad and Shanks, 2010). Muscular diseases like amyotrophic lateral sclerosis (ALS) may progress in patients to a lock-in state (LIS). Communication is difficult to impossible in this state because only a small level of voluntary muscular control remains. In complete LIS (CLIS), none remains. Individuals with LIS are largely limited to corporeal machine interfaces (CMI). These use BCIs through routes such as electroencephalography (EEG) or near-infrared spectroscopy (NIRS). The purpose of a CMI is to perform an action that matches the corresponding intent of the individual (Soraghan et al., 2008; Tai and Chau, 2009).

Routes of communication for subjects with LIS are available. These can be established using methods like small eye movements, event-related potential (ERP), and P-300 EEG paradigms from either visual or auditory stimulation. P-300 is the peak of a positive wave caused by a sharp voltage increase that takes place $300 \mathrm{~ms}$ after a meaningful stimulus is presented (Brower, 2005; Chatterjee et al., 2007; Birbaumer et al., 2008; Kayagil et al., 2009). Functional movements can be achieved using technologies such as intelligent wheelchairs or NMP (Song et al., 2007; Ju et al., 2009). Neuroprosthetics are also advantageous in restoring target innervations for bladder control and normal stimulation for the management of pain but are beyond the scope of this review (Garde et al., 2009).

Due to the size of the field and the rate of technological expansion, it is not possible to discuss all aspects of the following sections. The main focus of this review is to provide a holistic amalgamated overview of the most recent human in vivo techniques for implementing BCIs, bidirectional interfaces and neuroprosthetics. Even though neuroengineering is providing new methods for tackling current difficulties, neuroprosthetics and their related counterparts have been studied for decades. Recent progress in information and communication technology (ICT) is permitting the design of better systems with higher accuracies, repeatability, and system robustness.

In the following sections, the first concentrates on bidirectional interfaces. These are the integrating mechanism between recording and the relaying of information from and to the brain for the development of BCIs. It starts off by introducing the concepts of non-invasive and invasive recording of brain activity. This includes classical and innovative techniques like EEG and NIRS. Then the problems, such as gliosis, and solutions for (semi-) permanent implant biocompatibility such as innovative coatings, materials, and shapes are discussed. Aspects of powering implants and the transmission of their data through implanted pulse generators (IPGs) and wireless telemetry are taken into account. The final part of the section addresses how sensation can be relayed back to the brain to increase integration of neuroengineered systems with the body by methods such as micro-stimulation and transcranial magnetic stimulation (TMS).

The second major section concentrates on the various types of neuroprosthetics as well as how they operate. Visual prosthetics are discussed and the three types, dependant on implant location, are examined. Auditory prosthetics, being cochlear or cortical, are then addressed. Replacement hand and limb prosthetics are then considered. These are followed by sections concentrating on the control of wheelchairs, computers and robotics directly from brain activity as recorded by non-invasive and invasive techniques.

\section{BIDIRECTIONAL INTERFACES}

Bidirectional interfaces make use of mechanical and computer components. These provide rudimentary feedback that is operated by the brain activity of the subject, when normal function has been lost. This section goes into the details of: how data is recorded from subjects, via non-invasive and invasive techniques; the problems that are being encountered when trying to produce long-term clinical viability, via overcoming biocompatibility issues; the methods being implemented to transfer the recorded data for external processing; and how a haptic sense of feedback may be provided to the CNS from these systems. Figure 1 shows how the following subsections link together to achieve function.

\section{DATA RECORDING}

Brain-computer interfaces receive information from either of two recording types, being non-invasive and invasive techniques. As the processing of motor and sensory information is spread across neural populations, hundreds of recording centers are required to discriminate between the field potentials. Creating predictions of these population outputs may directly be compared with real-time external events (Chapin, 2004). As the distance between recording sources is decreased, the signals frequency content, amplitude, and spatial resolution will increase (Wilson and Williams, 2009). It is desirable to extract distinct, task-specific patterns of neural activity from particular activities (Eick et al., 2009).

Ideally the characteristics of these systems should include the following: user performance should require little effort because if they become fatigued, erroneous selection of targets by their brain activity will occur; generation of intense brain signals, having a high signal-to-noise ratio, which can be interpreted fast and 


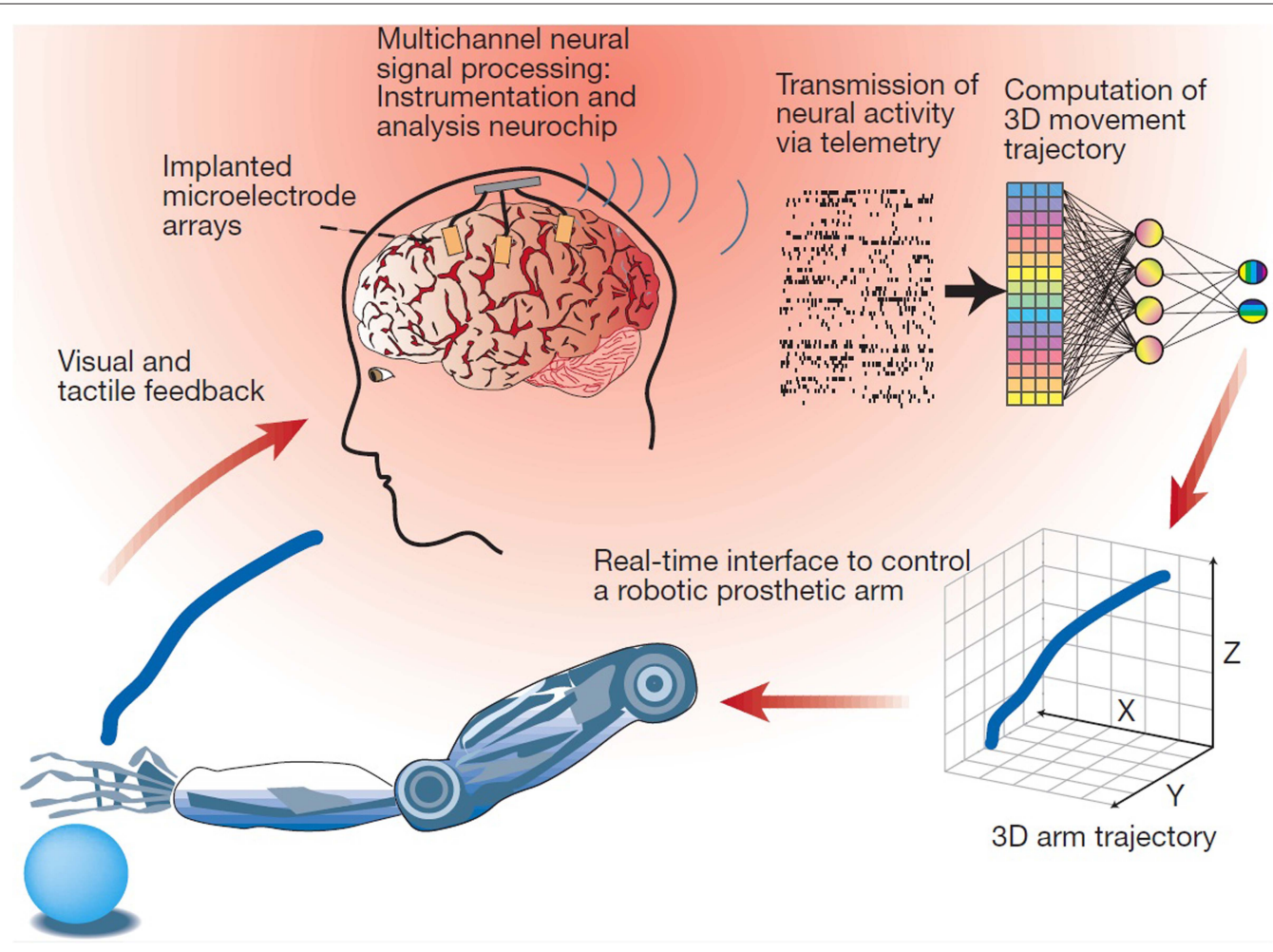

FIGURE 1 | Schematic description for a BMI that relies on the real-time sampling and processing of large-scale brain activity to control a robotic prosthetic arm. Multiple, chronically implanted, intracranial microelectrode arrays are used to sample the activity of large populations of single cortical neurons simultaneously. The combined activity of these neural ensembles is then transformed by a mathematical algorithm into continuous three-dimensional arm-trajectory signals that can be used to control the movements of a robotic prosthetic arm. A closed control loop is then established by providing the subject with both visual and tactile feedback signals generated by movement of the robotic arm. Reprinted with permission from Macmillan Publishers Ltd: Nature 409, 403-407 (Nicolelis, 2001), copyright 2001. reliably; users should be able to easily switch between thoughts so that they are able to control the patterns of their brain activity; outputs should be effective whilst providing user-friendly feedback (Coyle et al., 2007; Gerven et al., 2009).

\section{Non-invasive measuring of brain activity}

Non-invasive methods reflect the neuronal activity of large cell populations. Generally temporal resolution is very good but spatial resolution is poor. This may be attributed to the poor electrical conductance through bone and tissue (Gerven et al., 2009). The primary goals of BCIs and BMIs are obtaining high temporal and spatial resolutions when sampling motor neuronal activity (Garde et al., 2009). These techniques are not ideal for real-world application due to the size of the equipment and the poor spatial resolution. They acquire data from changes in magnetic fields, electrical current and oxygen consumption. The most common techniques are summarized in Table 1.

The unique signals in neuronal activity caused by specific states or mental processes are called signatures. The two signature types are "evoked" and "induced" responses, both are time-locked to an event. Evoked responses are phase-locked to an event; averaging these repeated responses will increase the signal-to-noise level. With regards to induced responses the power, not phase, is time-locked to an event. However the power of the specific frequency bands has to be calculated before it is averaged across trials. The response measured is referred to as an ERP, also called an event-related field (ERF; Gerven et al., 2009).

A P-300 ERP is a reflection of arousal, showing levels of attention. A positive P-300 wave occurs $300 \mathrm{~ms}$ from being presented with a meaningful stimulus. This ERP type is focused on goal selection, opposed to process control as seen in many other systems. Natural brain function resembles goal selection more closely because something entirely novel does not have to be taught to it. This is used for capturing the responses to "yes" and "no" operators. Highlighted groups are used to present choices; the field of choice is narrowed until the final selection is made. Each selection is an evoked P-300 potential, responding to the subjects stimulus reaction. Through training, ERPs are used to reliably operate BCIs at the same feasibility level as visually based BCI systems using the same operators (Nijboer et al., 2008; Finke et al., 2009; Furdea et al., 2009; Gerven et al., 2009; Kayagil et al., 2009). The need for training has been minimized or completely eliminated in some studies (Lin et al., 2010).

Event-related desynchronization (ERD) is a reduction in signal power in a specific signal band during a particular event. Both EEG and magnetoencephalography (MEG) make use of ERD. Platforms using ERD can distinguish between a state of relaxation and two more separable ERD states for operator selection. Subjects' movements 
Table 1 | Summary of non-invasive techniques for measuring brain activity.

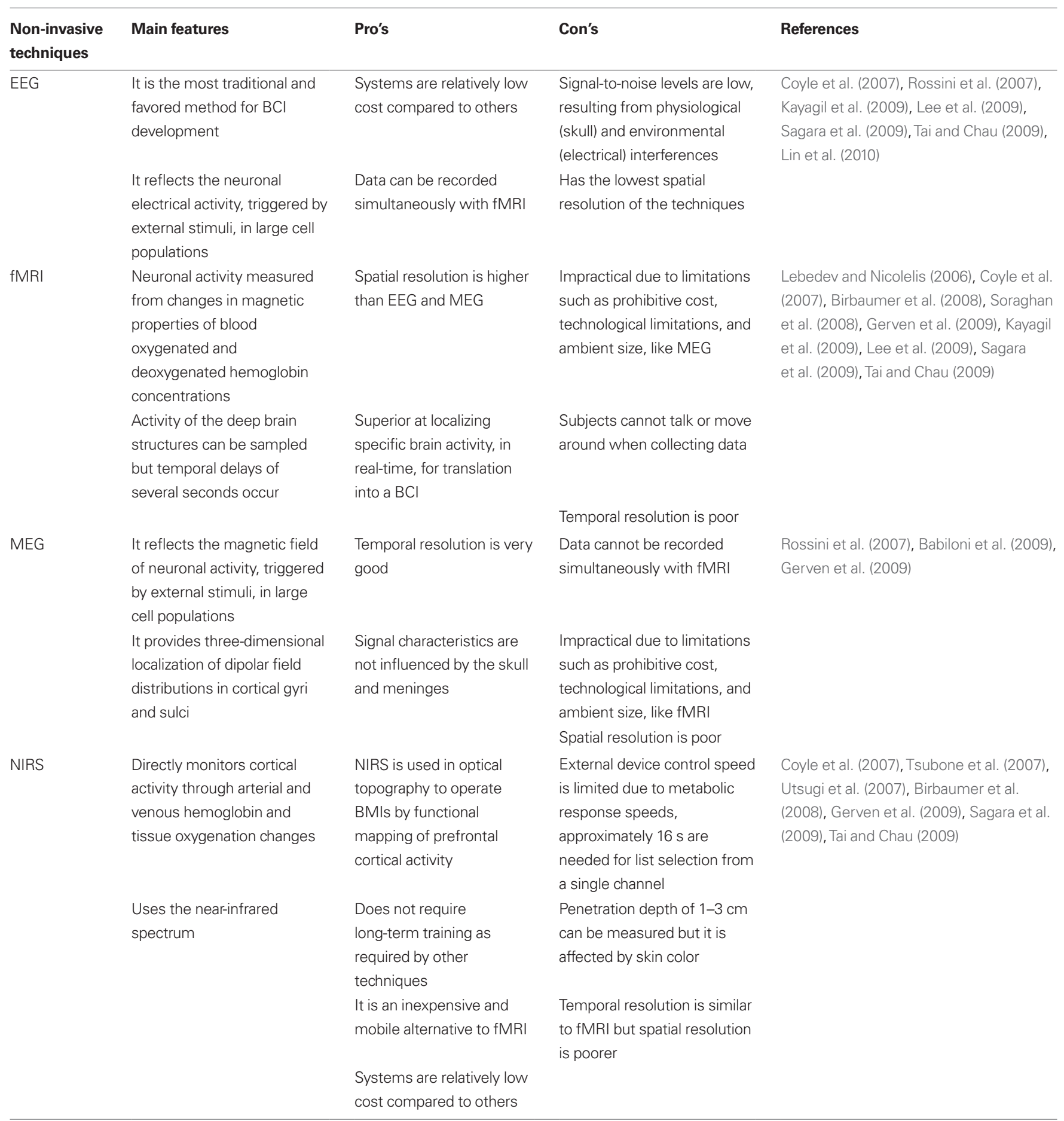

cause an ERD in the mu (sensorimotor) rhythm of their contra-lateral sensorimotor cortex (Chatterjee et al., 2007; Kayagil et al., 2009). The mu and beta frequency bands are reactive to both motor imagery and observation of biological movement. This has been used to link the activity of human mirror neurons with the mu rhythm. This rhythm reflects how premotor cortex visuomotor mirror neurons modulate the downstream primary sensorimotor neurons (Birbaumer et al., 2008; Gerven et al., 2009; Neuper et al., 2009).

\section{INVASIVE MEASURING OF BRAIN ACTIVITY}

Invasive methods achieve a high signal-to-noise ratio by eliminating the volume conduction problems caused by tissue and bone. Electrodes are directly placed onto the cortical matter. This makes excellent detection of high frequency oscillatory activity possible. However, surgery is required for the transcutaneous wire implantation. Local field potentials (LFP) sample the average neuronal potentials and spiking activity in the vicinity of the electrodes. 
Signals from thousands to millions of cells may be superimposed (Avestruz et al., 2008; Gerven et al., 2009; Kayagil et al., 2009; Wilson and Williams, 2009). Potential sources of LFPs include subthreshold synaptic currents, biophysical properties of the cell membranes, transmembrane currents, and electrical interactions (Donoghue et al., 2007). Single unit recording shows great promise for real-world applications due to compact size and high spatial resolution. The most common techniques are summarized in Table 2. These directly acquire electrical signal data from the neuronal populations.

To extract motor parameters from cortical areas, certain population sizes must be used to maintain prediction accuracy. This becomes poor when sizes fall to around 10-20 neurons. Neurondropping curves (NDC) calculate the neuron ensembles necessary for given BCI algorithms to accomplish certain performance levels. They predict accuracy as a function of simultaneously recorded neurons in any given session. This is calculated by measuring the performance of the entire neural population and then randomly dropping individual neurons until a critical level of performance is reached (Nicolelis and Lebedev, 2009). A few examples of MEAs are provided in Figure 2.

\section{PRODUCING LONG-TERM CLINICAL VIABILITY}

At this point, single unit recording holds the greatest potential for real-world applications of neuroprosthetics. The major obstacle to these devices is biocompatibility. Early electrodes could only reliably support in vivo recordings for several weeks as they usually failed within a short period of implantation. The two main reasons for this are gliosis and device failure (Moxon et al., 2004, 2007). Electrolytic tissue damage caused by the interface compromises neuronal stability over long periods of time (Garde et al., 2009).

In vivo MEAs in BCI and BMIs have several limitations that need to be overcome: low biocompatibility causes tissue damage and inflammation; three-dimensional (3D) electrode matrices must be designed as opposed to planar ones; fully implantable systems with thousands of recording channels are needed so that as many features as possible are reported, this can be done by handling large data throughputs in real-time from multiple neuronal areas, without compromising the information regarding critical neuronal activity; due to power and size requirements, there is a need for wireless, adaptive and distributed cortical interfaces; more efficient computer algorithms must be created; plasticity should be used to incorporate devices into the cortical representational areas, so that they feel part of the body; fully functional prosthetics must be able to perform complex movements, achieved through the integration of multiple separable brain signals (Lebedev and Nicolelis, 2006; Abu-Nimeh et al., 2009; Sodagar et al., 2009).

\section{The glial response}

Under normal conditions CNS cells do not regenerate axons like those of the peripheral nervous systems (PNS), this leads to permanent disability. Nervous tissue is easily damaged by fine movements of implanted foreign material like MEAs. Damage can be classified into acute and chronic categories (Moxon et al., 2004, 2007; Frewin et al., 2009; Garde et al., 2009; Rao and Winter, 2009; Straley and Heilshorn, 2009; Leach et al., 2010).

The acute injury response includes: inflammation from the foreign material and macrophage recruitment that is delayed by the blood brain barrier (BBB; Moxon et al., 2004, 2007; Rao and Winter, 2009; Leach et al., 2010); inflammation occurs quickly from protein absorption into the area between the implant and the neural surface (Straley and Heilshorn, 2009); damage to the BBB causes hypoxia, whilst also tearing neural processes. These lead to glial and neuronal death. This damage takes approximately 6 months to heal. Macrophages hinder cellular regeneration as they remove the myelin glycoprotein (Moxon et al., 2004, 2007; Rao and Winter, 2009; Leach et al., 2010).

In chronic injury, blood serum proteins are released into the brain. This starts a cascade to remove debris and damaged tissue and if severe, gliosis may occur. Gliosis causes astrocytes to proliferate which create a glial scar; this protects the brain from further injury or infection. In light of this, it is doubtful that completely eliminating gliosis will be beneficial for long-term biocompatibility (Moxon et al., 2004, 2007; Garde et al., 2009; Rao and Winter, 2009; Shoval et al., 2009; Leach et al., 2010).

Table 2 | Summary of invasive techniques for measuring brain activity.

\begin{tabular}{|c|c|c|c|c|}
\hline Invasive techniques & Main features & Pro's & Con's & References \\
\hline \multirow[t]{2}{*}{$\begin{array}{l}\text { Electrocorticography } \\
\text { (ECoG) }\end{array}$} & $\begin{array}{l}\text { Records mu, beta, and } \\
\text { gamma sensorimotor } \\
\text { rhythms }\end{array}$ & $\begin{array}{l}\text { Good detection of high } \\
\text { frequency oscillatory activity } \\
\text { from the high signal-to-noise } \\
\text { ratio }\end{array}$ & $\begin{array}{l}\text { Spatial resolution is lower } \\
\text { than single unit recording }\end{array}$ & $\begin{array}{l}\text { Coyle et al. (2007), Soraghan et al. } \\
\text { (2008), Gerven et al. (2009), Kayagil } \\
\text { et al. (2009), Wilson and Williams } \\
\text { (2009), Lin et al. (2010) }\end{array}$ \\
\hline & $\begin{array}{l}\text { Similar to EEG but more } \\
\text { data is recorded } \\
\text { Each electrode records } \\
\text { one channel }\end{array}$ & $\begin{array}{l}\text { Spatial resolution of } \\
\text { sensorimotor rhythms is high } \\
\text { Uses } 64 \text { channels or more }\end{array}$ & & \\
\hline Single unit recording & $\begin{array}{l}\text { Has the highest spatial } \\
\text { resolution of all } \\
\text { techniques } \\
\text { Single or multi-neuron } \\
\text { spiking and LFPs can be } \\
\text { recorded }\end{array}$ & $\begin{array}{l}\text { LFP technique is similar to } \\
\text { ECoG but higher spatial } \\
\text { resolution is obtained }\end{array}$ & $\begin{array}{l}\text { Recordings are not useful } \\
\text { for extracting motor or } \\
\text { sensory information }\end{array}$ & $\begin{array}{l}\text { Chapin (2004), Smith et al. (2004), } \\
\text { Avestruz et al. (2008), Gerven et al. } \\
\text { (2009), Kayagil et al. (2009) }\end{array}$ \\
\hline
\end{tabular}



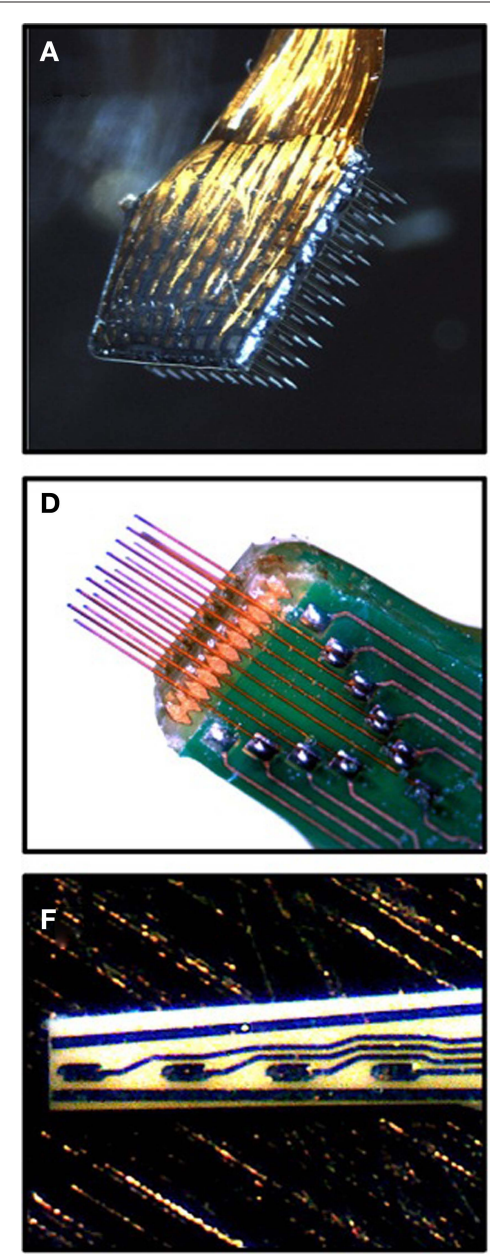
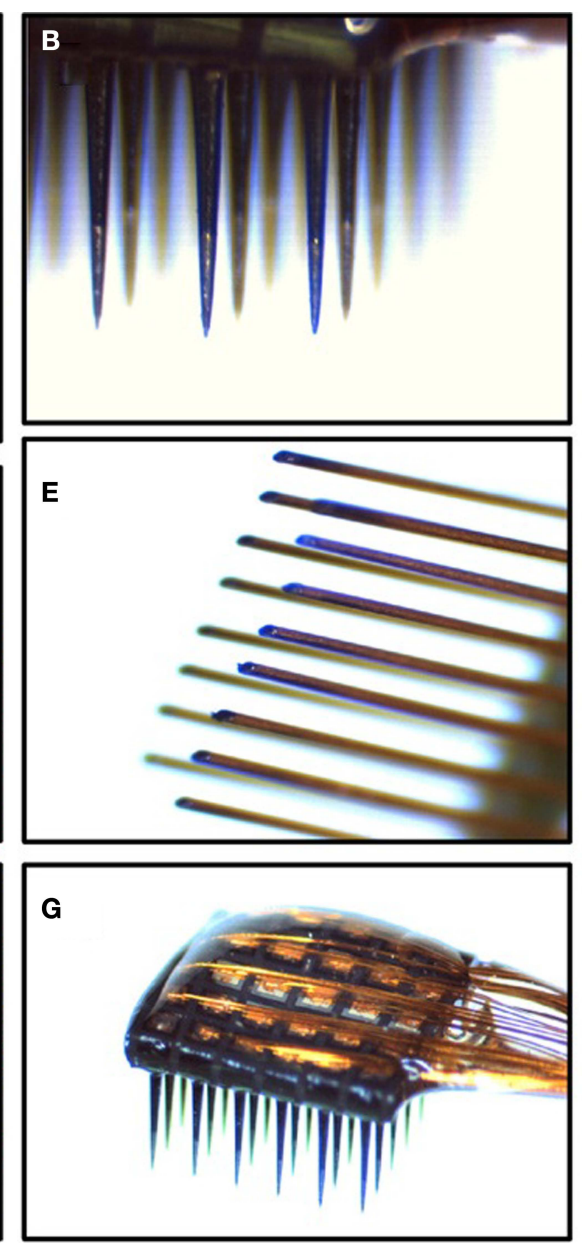

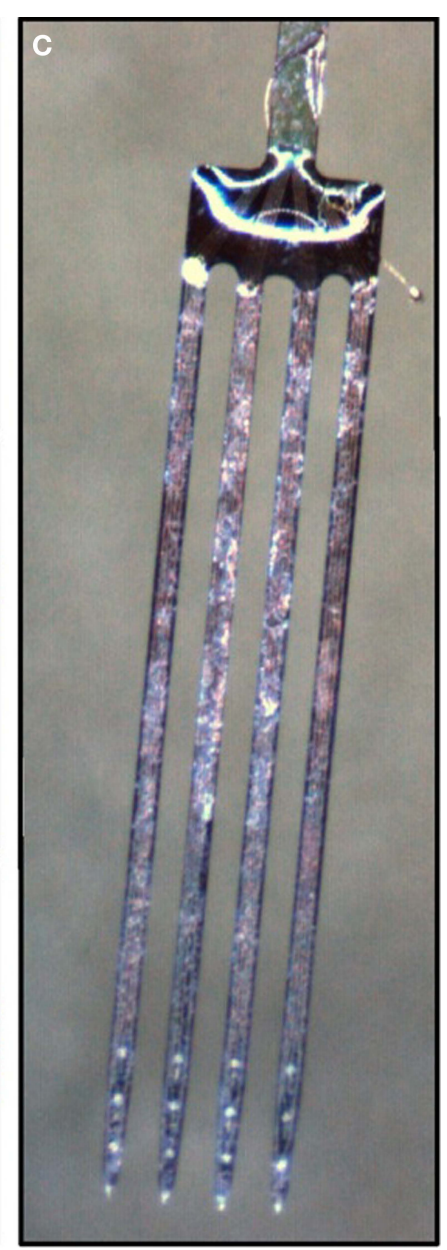

FIGURE 2 | Example images of MEAs. (A) Cyberkinetics silicon-based 100-channel MEA. (B) View of recordings sites on the Cyberkinetics array. (C) NeuroNexus silicon-based MEA shanks. (D) Tucker-Davis Technologies (TDT) microwire MEA. (E) View of recording sites on the TDT microwire array. (F) Moxon thin-film ceramic-based MEA. (G) View of bond pads on a 36-channel Cyberkinetics array. Reprinted with permission from Elsevier: Brain research 1282, 183-200 (Ward et al., 2009$)$, copyright 2009.

Scars are non-conductive, they block the interfacing surface between the cells and electrodes. Encapsulation of the device from scar tissue formation is caused by the foreign body response; this occurs from a lack of extracellular matrix (ECM) interactions which are crucial in tissue regeneration. Neuronal density around the foreign material is decreased as glial cells push neurons back; opposed to a loss of neurons (Moxon et al., 2004, 2007; Rao and Winter, 2009; Shoval et al., 2009; Leach et al., 2010). Gliosis increases electrode impedance which is negatively correlated to signal clarity. Increased scarring decreases the signal-to-noise ratio and reduces the number of active electrode sites. To sustain neural responses over time, neurointerfaces must be recalibrated. From time to time the interface voltage must be increased prior to recording sessions to compensate for the increased impedance from encapsulation. Eventually this will lead to failure of the device (Zhong and Bellamkonda, 2008; Frewin et al., 2009; Garde et al., 2009). In the PNS, fibrous tissue encapsulates the electrodes with the same consequences (Bossi et al., 2009).

\section{Coatings}

Biomaterials are being used to overcome the problem of encapsulation (Lebedev and Nicolelis, 2006; Rao and Winter, 2009). Integration of implants with tissues is positively correlated with the density of nanostructures, up to the micrometer scale, on their surface. The more nanostructures present, the greater the integration (Straley and Heilshorn, 2009). ECM coatings promote growth and the attachment of cells which reduces encapsulation (Ahmed et al., 2006).

Extracellular matrix interactions promote differentiation, migration, axonal regeneration, neutrite elongation, and adhesion (Rao and Winter, 2009; Shoval et al., 2009). These molecules also act as a neuro-protective surface to protect the tissue from the implant. This is due to the reduction in movement of the electrodes; from the interaction between the ECM of the neural tissue and that of the implant (Moxon et al., 2004).

Coating processes. Extracellular matrix molecules are attached to implant surfaces using various methods. Natural or synthetic films are one of the options. Natural materials include collagen, gelatine, 
and chitosan. Chitosan is a biodegradable polysaccharide that is derived from chitin. However natural materials experience batchto-batch variation as they are isolated from animal or human tissues (Zhu et al., 2003; Rao and Winter, 2009). Synthetic materials include polymers that can be coated as polyamide nanofibers to create a completely synthetic $3 \mathrm{D}$ matrix. This can be done using electrospinning which is a technique that uses electrostatic fiber formation to produce polymer fibers. Electrical forces are used to produce fiber diameters ranging from $2 \mathrm{~nm}$ up to several micrometers. To further increase the ECM characteristics of these matrices, peptides such as laminin and human teasing-C may be covalently attached to them (Ahmed et al., 2006; Birbaumer et al., 2008; Koh et al., 2008; Bhardwaj and Kundu, 2010).

Alternatively the sol-gel process can be used to attach ECM molecules to implant surfaces. Sol-gel transitions a soluble liquid into a solid, yet porous network of gel. Processing is accomplished at low temperatures, this limits damage to the electrodes and a high degree of thickness uniformity is achievable over complex geometric shapes. Other implant improvements are mechanical strength and the prevention of metallic corrosion. This technology offers highly specific control over the coatings chemical composition and microstructure, which is combined with ease of fabrication. The gels created may also be used to carry absorbable drugs (Ben-Nissan and Choi, 2006; Gupta and Kumar, 2008).

Covalent linking of CRC-triblock protein polymers is another strategy for creating hydrogel networks. These can physically adsorb a variety of substrate materials as well as display ECM peptides. The two "C's" are self-connecting leucine zipper domains and the " $\mathrm{R}$ " is a disordered center block that contains a cell binding domain (Fischer et al., 2009). In addition to the previously discussed methodologies, molecules may be incorporated into biomaterials by direct surface coating through techniques such as electrostatic self assembly (ESA), Langmuir-Blodgett deposition, electropolymerization, polyelectrolyte multilayer films, microcontact printing, and photoresist-liftoff (Chluba et al., 2001; James et al., 2004).

Coating materials. The technologies discussed above may be used to increase implant biocompatibility by carrying soluble factors or by tethering modular protein polymers to the implant surface (BenNissan and Choi, 2006; Gupta and Kumar, 2008; Rao and Winter, 2009). Ideally the ECM on the implant surfaces should have high porosity being $70 \%$ or more, high interconnectivity, and a high surface-to-volume ratio (Ahmed et al., 2006).

Soluble factors can be used to incorporate neurotrophic media into the electrodes themselves, such as anti-inflammatory compounds like dexamethasone. In regards to tethered biomolecules; two of the methods being employed are neuronal growth factors and modular protein polymers. Neuronal growth factors include nerve growth factor (NGF), brain-derived neurotrophic factor, laminin, and collagen (Lebedev and Nicolelis, 2006; Rao and Winter, 2009). Modular protein polymers include enzymes, proteins, and other biomolecules (Gupta and Kumar, 2008). These imitate ECM characteristics and are reproduced rapidly by cloning. Their domains are similar to the ECM proteins elastin, laminin, neural cell adhesion molecule (NCAM), and fibronectin. These increase neuronal cell adhesion and neutrite elongation (Straley and Heilshorn, 2009).

\section{Implant fabrication materials}

Electrode materials must provide good performance for electrical stimulation and recording (Shoval et al., 2009). Noble bare metals have low Warburg capacitance and a high charge injection limit, which is why they are often ignored for the stimulating small neural areas (Wilks et al., 2009). Warburg low current-density capacitance $\left(C_{\mathrm{w}}\right)$ is used to compare the impedance of metal electrodes. The higher the Warburg capacitance, the lower the impedance at the tissue-electrode interface. When using direct current (DC) in applications such as IPGs, there is no distinction between resistance and impedance (Geddes and Roeder, 2003). Reversible charge injection limit is the maximal amount of charge per pulse that can move to electrode surroundings and cause a reversible chemical reaction. Charged pulses from electrodes create electrochemical potentials; these may be reversed by a second current pulse of the opposite polarity (Horch and Dhillon, 2004). Following are a few examples of commonly used fabrication materials. The most common materials are summarized in Table 3.

\section{Physical shapes, geometries, and characteristics}

Efficient recording and stimulation is highly dependent on contact between the electrode and the cell, electrode and array geometry, and the degree of resistance in each electrode (Smith et al., 2004; Eick et al., 2009). Smaller electrodes have higher interface impedance. If the interface is sculpted as the comparable amalgamation of a Faradaic resistance and a double layer capacitance, the interface impedance is indirectly proportional to the electrode area (Wei and Grill, 2009).

Rougher electrodes have larger surface areas which optimizes coupling between cells and electrodes. However, it must be possible for cells to adhere to the surface (Shoval et al., 2009). Nanotexturing the surface of electrodes by electrodeposition, with substances such as gold, greatly increases the roughness of the electrodes surface (Cottman, 2009). Electrodes with extremely rough surfaces, at a scale of tens of nanometers to micrometers, act as superb electrochemical conductors whilst also creating a substrate for neuronal growth. This provides an unmediated, direct coupling interface between neurons and electrodes which increases signal-to-noise ratios (Sorkin et al., 2006; Shoval et al., 2009). Porous substances reduce the extent to which neurons are pushed away by gliosis of implanted arrays. Porous silicon increases neurite extension more than non-porous silicon (Moxon et al., 2004).

Cyberkinetics Neurotechnology Systems Incorporated designed a silicon array called the Utah array. It consisted of multiple electrodes that were able to access the columnar structure of the cerebral cortex (Rousche and Normann, 1998). These arrays are still being utilized as the underlying architecture for some new MEA systems (Donoghue et al., 2007; Pancrazio and Peckham, 2009). In array design, a major challenge is obtaining high current densities in small tip sizes while staying away from values that cause MEA degradation. Electrode tips are conical in shape. Due to blunting, tips shaped at $40^{\circ}$ show increased current density when compared to tips of $90^{\circ}$ (Moxon et al., 2007; Yaeli et al., 2009). The lower limit for electrode size in planar stimulation is about $2 \mu \mathrm{m}$. This is a reference point to minimize electrode size and increase the spatial density in MEAs (Smith et al., 2004). 
Table 3 | Summary of materials used for implant fabrication.

\begin{tabular}{|c|c|c|c|c|}
\hline Material & Main Features & Pro's & Con's & References \\
\hline
\end{tabular}

Iridium oxide (IrOx) Commonly used in planar electrodes and signal-to-noise levels are similar to platinum black electrodes

Has a very high Warburg capacitance, low charge injection limit and low impedance

Poly 3,4ethylenedioxythiophene

Silicon and ceramics
High ionic conductivity and large surface area provide extremely effective charge transfer with low impedance across its spectrum High signal-to-noise ratios are attainable

Silicon is used as the structural backbone for most electrode arrays
Currently viewed as the best interface material for cortical stimulation, also used for stimulating and recording activity of the heart and retinal tissue Highly porous structure provides a large electrochemical surface area that provides interface stability over long periods

Charge injection limits start at the same level as the IrOx limit but much higher limits are possible

Electrochemically stability allows long-term use in PBS Biomolecules may be immobilized on its surface

Silicon electrodes have unsurpassed superiority in shape, spacing, texture, and size
Electrode properties are preserved when stored in dry conditions but phosphate buffer saline (PBS) they must be reactivated and cleaned daily for continued use

Electrodes initially show lower impedance, however use causes a gradual impedance increase to that of uncoated probes

\section{Silicon electrodes are not} chemically resilient which leads to brittleness, fracture and fragmentation
Eick et al. (2009), Gawad et al. (2009), Wei and Grill (2009), Wilks et al. (2009)

Wilks et al. (2009), Leach et al. (2010)

Moxon et al. (2004, 2007), Smith et al. (2004), Zhong and Bellamkonda (2008), Bossi

et al. (2009), Frewin et al. (2009), McCarthy et al. (2009) 
Table 3 | Continued

\begin{tabular}{|c|c|c|c|c|}
\hline Material & Main Features & Pro's & Con's & References \\
\hline & $\begin{array}{l}\text { Silicon electrode } \\
\text { fabrication is } \\
\text { comparatively easy } \\
\text { which makes it popular } \\
\text { Ceramic dielectric } \\
\text { constants are higher } \\
\text { which allows for smaller } \\
\text { features } \\
\text { Ceramic-silicon hybrids } \\
\text { are produced to offer } \\
\text { intermediate } \\
\text { characteristics such as } \\
\text { improved microelectrode } \\
\text { strength from increased } \\
\text { flexibility, compared to } \\
\text { ceramics using alumina }\end{array}$ & $\begin{array}{l}\text { Silicon nitride }\left(\mathrm{Si}_{3} \mathrm{~N}_{4}\right) \text { acts as } \\
\text { an insulator, the thicker it is } \\
\text { the lower the electrode } \\
\text { capacitance } \\
\text { Polyimides are often } \\
\text { supplemented to alleviate } \\
\text { internal stress } \\
\text { Ceramics are often used in } \\
\text { electrode fabrication } \\
\text { instead of silicon as } \\
\text { superior insulation is } \\
\text { provided by ionized alumina }\end{array}$ & $\begin{array}{l}\text { Silicon electrodes are poorly } \\
\text { insulated }\end{array}$ & \\
\hline $\begin{array}{l}\text { Amorphous silicon } \\
\text { carbide (a-SiC) }\end{array}$ & $\begin{array}{l}\text { It is extremely hard yet } \\
\text { still flexible and does not } \\
\text { expand in liquid } \\
\text { environments } \\
\text { It is chemically inert to } \\
\text { acids, alkalis and salts } \\
\text { Has different polytypes } \\
\text { which are crystalline } \\
\text { stacking types that each } \\
\text { display different } \\
\text { mechanical and electrical } \\
\text { properties }\end{array}$ & $\begin{array}{l}\text { It is very permissive to the } \\
\text { free movement of neural } \\
\text { lamellipodia } \\
\text { Currently it is used as a } \\
\text { coating for replacement hip } \\
\text { joints and angioplasty } \\
\text { stents } \\
\text { Its production uses many of } \\
\text { the same processes used } \\
\text { in the silicon industry which } \\
\text { lowers costs }\end{array}$ & & Frewin et al. (2009) \\
\hline
\end{tabular}

Electrode placement geometry can be used to maximize the stimulation efficiency and decreases power requirements. One way to achieve this is by using serpentine variation which increases the electrode perimeter without increasing its area. In planar electrodes, serpentine perimeters may be up to four times larger than the circular configuration. Increased perimeter size does not affect impedance but power consumption may be reduced by up to $10 \%$. Axons further from the electrode surface are activated more efficiently by this arrangement; the further the axon, the lower its threshold current. In the serpentine configuration, spreading of tissue resistance is reduced, which reduces power requirements regardless of the distance between axons and electrodes. Tissue damage increases from the increased current density of the electrodes surface, thus serpentine perimeters may be more damaging than circular ones (Wei and Grill, 2009).
Floating electrodes use flexible connecting cables made from polymer substrates. They connect recoding sites to external adaptors that are anchored to the skull. Compared to more rigid electrodes, strain is relieved and chronic tissue damage is minimized. However, they are more likely to buckle on insertion. As a result they must be implanted by hand which decreases implant accuracy. To overcome buckling, insulated tungsten micro-wires can be used to provide sufficient structural integrity for accurate implantation (Moxon et al., 2004; Patrick et al., 2008). Rigid electrodes may also be formed into extremely sharp shanks which allows for quick insertion. This causes minimal damage to the surrounding tissues (Frewin et al., 2009).

\section{THE TRANSFER OF RECORDED DATA}

Early in vivo MEAs relied on hardwired power. The NeuroNexus silicon array, also called the Michigan microelectrode system is historically important as it made use of multilead silicon ribbon 
cabling. This cabling system was a significant step forward in regards to providing reliable transfer of signal information to and from an in vivo environment (Hetke et al., 1994). Two strategies are currently being utilized to eliminate the use of hardwired power, they are IPGs and wireless telemetry (Song et al., 2007; Chae et al., 2008; Rizk et al., 2009; Sodagar et al., 2009; Wei and Grill, 2009; Lin et al., 2010).

These systems do not protrude through the skin so infection risk is minimized (Rizk et al., 2009). IPGs utilize batteries to provide neuronal stimulation and these have to be surgically replaced once depleted. Battery lifetime may be prolonged by reducing power requirements. Alternatively smaller batteries may be used which will reduce the IPG size (Wei and Grill, 2009). IPGs can be placed in areas other than the head such as the pectoral region, with the electrodes going to specific neuronal target areas (Avestruz et al., 2008).

The second strategy uses wireless telemetry. Forward telemetry provides power over a wireless link via radio frequencies (RF). This inductive RF link provides for programming the clock signals and commands that ensure accurate data time sampling. Backward telemetry sends the recorded information to external hosts as digital data streams of infrared (IR) light pulses. As the need for batteries is eliminated, these innervations allow for smaller interfaces with increased implant life. Fully implantable 96-channel acquisition systems are possible that work from up to several meters away (Song et al., 2007; Chae et al., 2008; Soraghan et al., 2008; Rizk et al., 2009; Sodagar et al., 2009). Bluetooth or wireless local area network (WLAN) may be used for data transmission (Lin et al., 2010).

Compressed sensing is a means to drastically reduce the quantity of bandwidth needed for data transmission through telemetry. This data acquisition protocol allows only the data that would be left after compression to be collected, as opposed to collecting this data along with compressible data only to lose the latter after initial compression. It is achieved by exploiting the sparse depiction of recorded data. Using a compressed sensing protocol it is possible to reduce noise levels in the neuronal data, sort and detect spikes, whilst monitoring the firing rates of individual neurons (Donoho, 2006; Abu-Nimeh et al., 2009).

Wireless telemetry of EEG data allows for acquisition in realworld environments where subjects can move freely. Wireless neurointerfaces overcome one of the current major problems in MEAs, being the breakage of the wires used to transmit the sampled neuronal activity. In conjunction with stable recordings over long-term implantation, the potential applications are immense (Garde et al., 2009). The systems front end may be integrated in wearable devices such as sunglasses, headbands, or baseball caps. These systems can potentially: monitor epilepsy in children as symptoms are often misdiagnosed; provide vibrotactile feedback sensations; operate telephone keypads displayed on personal computer (PC) monitors operated by steady-state visually evoked potentials (SSVEP). The SSVEP model is reliant on targets that are flashed at different rates, this creates SSVEPs at different frequencies from which a computer determines the target which is prominent (Kayagil et al., 2009; Lin et al., 2010).

A newly emerging technology uses micro-optical arrays. Fiber optic cables transmit low energy light which can be converted to power. These same fibers can transmit the high bandwidth signals from over 100 electrodes back toward the light source. This method shows no electrical artifacts and has a stimulation specificity of less than $400 \mu \mathrm{m}$. Transient optical neural stimulation solves some of the current spatial resolution issues (Donoghue et al., 2007; Konrad and Shanks, 2010).

\section{SENSORY FEEDBACK TO THE CNS}

Feedback of tactile, proprioceptive and vibratory information to the somatosensory areas is being researched (Lebedev and Nicolelis, 2006; Cipriani et al., 2009). Micro-stimulation is one means to relay information directly, or via peripheral nerves, to the sensory cortex (Garde et al., 2009). The most common means of relaying tactile information to the CNS is TMS. It also has the potential application of reactivating dormant cortical areas following a stroke. Use of this technique activates plasticity in neural components and may also affect blood flow. Pulses reach a depth of approximately $2 \mathrm{~cm}$, due to their rapid decay which provides low spatial resolution. Pulses delivered to specific areas convey somatomotor sensations such as finger movement through evoked motor potentials (EMP) of the primary motor cortex, or phosphenes by stimulating the visual cortex (Huerta and Volpe, 2009).

The weak magnetic pulses of TMS can stimulate neurons, as their ion channel density is higher than other cell types. TMS pulses cause action potentials that release neurotransmitters. Most cortical neurons release the excitatory neurotransmitter glutamate, a smaller portion release the inhibitory neurotransmitter gammaaminobutyric acid. Another group of neurons have long axons from different nuclei of the brain that project to the cortex. When stimulated these may cause the release of acetylcholine, dopamine, noradrenalin, and serotonin from the nuclei. Weak TMS pulses may therefore activate neuromodulatory pathways through excitatory and inhibitory neurons creating feedback and feed-forward loops (Huerta and Volpe, 2009).

\section{NEUROPROSTHETICS}

Neural prosthetic implants show many potential uses for recording neuronal activity and stimulating the CNS and PNS (Straley and Heilshorn, 2009). The key goal of many neuroprosthetics is: operation through closed loop BCI or BMI systems, with a channels for the relaying of tactile information (Chatterjee et al., 2007); to be efficient these systems must have neural interfaces that work in a consistent manner for as long as possible; they must be able to adapt recording to changes in neuronal populations; and tolerate physical real-life environmental factors (Ryu and Shenoy, 2009).

\section{VISUAL PROSTHETICS}

Visual prosthetic development has one of the highest priorities in the biomedical engineering field (Panetsos et al., 2009). Complete blindness from retinal degeneration arises from diseases such as Leber's congenital amaurosis (LCA) or age-related macular degeneration (AMD or ARMD). These cause dystrophy of photoreceptor cells (Shoval et al., 2009). Functional, yet rudimentary vision can be achieved by converting images into binary pulses of electrical signals and delivering them to the visual cortex. Sensations created are in the form of bright spots referred to as phosphenes or visual perception patterns (Morillas et al., 2007; Quiroga et al., 2007; Panetsos et al., 2009). 
This technology uses one of three possible pathways. Firstly, retinal implants to replace photoreceptor function. Their implantation and stabilization are difficult due to retinal fragility. However, implementation is easier than other visual prosthesis because far less complicated information is needed for stimulation. Secondly, optic nerve implants allow poor control over position and size of the evoked phosphenes. Finally, visual cortex implants use electrodes that require high electrical current. This negatively affects individuals over time (Morillas et al., 2007; Panetsos et al., 2009). These implants, opposed to optic nerve implants, provide higher spatial resolution for visual processing. This makes electrode design easier. To obtain significant spatial resolution, these prosthetics may also be implanted in the lateral genticulate nucleus (LGN) of the thalamus (Konrad and Shanks, 2010).

The Retinotopic principle states that the stimulation of two close retinal photoreceptors activates two close visual cortex neurons. However, at the cortex, this pattern suffers non-conformal and non-linear deformation. A great deal of plasticity is needed for these new patterns to be perceived as older perceptions once were; from a time before sight loss. The visual cortex does not represent a pixilated image but rather a complex visual motion with preferences that are directionally tuned (Konrad and Shanks, 2010). Pattern input may be altered, upon data analysis of the visual cortex, from activation of individual retinal phosphenes (Morillas et al., 2007). It has been estimated that, restoring visual perception to a point where surroundings are navigated, may be achieved with an array of 625 electrodes with $20 \mu \mathrm{m}$ spacing. Currently most devices use up to only 16 electrodes (Shoval et al., 2009).

In regards to subjects with CLIS, the auditory system is not compromised and may be used to communicate via a BCI. As documented in blind subjects, ALS patients develop a greater sense of hearing that allows them to focus more easily on auditory stimulation. Small eye movements are usually used to communicate. When this is not possible, ERPs are usually used to communicate (Birbaumer et al., 2008; Nijboer et al., 2008; Zhong and Bellamkonda, 2008; Furdea et al., 2009).

\section{AUDITORY PROSTHETICS}

Cochlear implants use electrical signals that directly stimulate the sensory epithelium of the basilar membrane, to produce auditory stimuli. The highest levels of success have been seen in subjects who had some sense of hearing during their critical developmental periods. Better resolution of sensory input is achieved by providing it to the cortex, rather than the auditory nerve. These implants may be placed into: the cochlear nerve/pons junction when the auditory nerve has been damaged; the cochlear nucleus, specifically the lateral foramen of Luschka; or into the inferior colliculus being more distal sensory circuitry (Ryu and Shenoy, 2009; Konrad and Shanks, 2010).

Auditory stimulus alone can be used for pinpointing specific letters on a PC monitor, displayed by a BCI. EEG is used for specific coordinate selection, in a matrix based structure, by focusing on ERPs of the mu rhythm. A more accurate averaged performance is achieved using auditory ERP spellers, rather than visual ERP spellers as an accuracy of $100 \%$ is possible (Furdea et al., 2009).

\section{REPLACEMENT HAND AND LIMB PROSTHETICS}

To functionally replace an amputee's limb with a robotic one, desirable aspects include: decoding user intentions to perform the desired motions; supplying sensory feedback to provide perception of the device in the environment; providing users with the feeling of natural control by attaining a sense of ownership from perception as part of the body. The device must provide feedback to the brain in order to achieve this (Lebedev and Nicolelis, 2006; Cipriani et al., 2009; Garde et al., 2009).

Currently, artificial limbs can only relay restricted sensory feedback due to their limited bandwidth. Commercially available prostheses are difficult to control because they offer no tactile or proprioceptive feedback. One of their largest problems is that there is no sense of ownership (Cipriani et al., 2009; Garde et al., 2009). Ownership is created by long-term prosthetic use where they are directly controlled by brain activity. It leads to remapping, through plasticity, of the cortical and sub-cortical areas (Lebedev and Nicolelis, 2006).

Cognitive burden occurs because users primarily rely on visual feedback for neuroprosthetic use (Garde et al., 2009). To free subjects from the need to maintain visual attention on the actuator, vibrotactile feedback must be provided. The haptic senses that relate to grasping force can be represented by vibrotactile intensity: high intensities for squeezing objects; low intensities for releasing them; constant intensities for maintaining a steady hold (Chatterjee et al., 2007). Functional electrical stimulation (FES) is used to substantially improve grasp function in neuroprosthetic use, yet voluntary shoulder and elbow function is required (Muller-Putz et al., 2009; Pancrazio and Peckham, 2009).

Near-infrared spectroscopy can be used as an on/off switch for BCI based robotic hands. This is achieved through timing estimation of movement for a learned network, which uses brain signals of the pyramidal area. These signals differentiate between the specific limb muscles that the subject is concentrating on (Tsubone et al., 2007; Micera et al., 2008). Future research is working toward lighter anthropomorphic transradial prosthesis, which will have electromyographic (EMG) signal processing embedded with tactile systems to provide feeling to the amputee. The present bottleneck in this technology is the EMG control algorithms (Cipriani et al., 2009). Signals are recorded from motor cortex activity that is not necessarily linked to the required task. These are used to perform desired movements using predefined grasping patterns. In these cases, extension of the arm and fingers are controlled using different patterns of motor activity (Micera et al., 2008).

Overlapping motor neuron collections form populations in the motor cortices process numerous motor parameters. Single cortical neurons may simultaneously contribute to several parameters (Lebedev and Nicolelis, 2006). Mathematical analysis is used to extract motor signals from populations. Information from the primary motor, premotor, somatosensory, and parietal cortices is used to calculate neural weightings (Chapin, 2004). Training of the non-invasive systems discussed above for controlling arm and hand prosthetic movement requires three stages: offline training of the algorithm; online tuning with periodic adjustments; and mutual adaptation through biofeedback (Micera et al., 2008).

Movement direction is gauged from a vector that encompasses direction, velocity and force rather than the contraction of individual muscles. This is pertinent when extracting information for 
controlling motor based prosthetics. Complex movement signals can be extracted with less than 100 channels. Robotic arms or computer cursors may be controlled directly, in a real-time environment from this analysis (Chapin, 2004; Nicolelis and Lebedev, 2009; Konrad and Shanks, 2010). However throughputs of more than $1 \mathrm{bit} / \mathrm{s}$ are extremely difficult to achieve using non-invasive methods (Micera et al., 2008).

Invasive methods for prosthetic control are becoming available. However, gliosis is still a major issue that needs to be overcome and the effects of direct stimulation need to be considered. Direct stimulation may cause undesired muscle contraction or cause reorganization through plasticity of the somatosensory cortex to create "phantom limb" syndrome by inciting false sensations (Micera et al., 2008). A gripping neuroprosthetic device can be controlled with as little as 32 electrodes (Brower, 2005). Various invasive and non-invasive strategies are available for controlling these prosthetics through the PNS, however these are beyond the scope of this review (Navarro et al., 2005).

\section{WHEELCHAIR USE}

A large amount of equipment has been developed to improve quality of life for the elderly and disabled. Electric wheelchairs are embedded with computers and sensors to give them rudimentary intelligence. The two major techniques that have been developed are: auto navigation for obstacle detection and avoidance; and user dependant interfaces. Over the years a multitude of non-invasive and invasive techniques have been implemented for user dependant wheelchair interfaces (Ju et al., 2009).

For the severely disabled, conventional methods of wheelchair operation may not be sufficient. Two of the methods that have been proposed for these cases are: facial feature use to operate the wheelchair through IR thermography (Ju et al., 2009; Memarian et al., 2009); intelligent brain actuated wheelchairs designed to allow to operation from subject's mental commands (Galán et al., 2008). Infrared thermography uses deep breathing, blinking or opening of the mouth as device commands. The system comprises of a feature detector, feature recognizer, and a converter. Thermal imaging cameras are used, so sensors do not need to be attached to the users, thus making them hygienic and eliminating the risk of choking. Inclination of the face is used for steering and mouth shape is used for acceleration or stopping. It overcomes several computer based vision access pathway limitations because it is not affected by: various lighting levels; extraneous movements; body posture; and skin color variation, which makes it independent of race (Ju et al., 2009; Memarian et al., 2009).

Alternatively, intelligent brain actuated wheelchairs have been designed to allow subjects to operate them using mental commands. Statistical machine learning is used to design optimal classifiers. This allows subjects to choose mental tasks that they are more comfortable with. The EEG patterns produced are selected by maximizing their separability to other commands. The subjects must be able to perform commands, even under stressful and distracting conditions. Even though control systems need to be calibrated for each subject, the procedures are the same for all so lengthy training is unnecessary (Galán et al., 2008).

\section{INTERACTION WITH ROBOTS}

Robotic arms can be controlled by systems, such as functional magnetic resonance imaging (fMRI), in a real-time environment. Neuronal activity is obtained from the cortical somatomotor areas of hand movement, being the dorsal precentral gyrus and the anterior part of the central sulcus. Mu and beta rhythms are decreased by observing an experimental hand grasping. Through interpretation, it can be used to adjust horizontal and vertical movement in a two-dimensional (2D) environment. Feedback from the subjects' visual field then adjusts cortical activation while controlling the robotic arms movement (Lee et al., 2009; Neuper et al., 2009).

New daily activities for disabled and able-bodied persons are provided by BMI use. A subject's visual perspective can be placed directly into another environment causing augmented reality (AR). Robot agents in this environment can be operated through their visual perspective. Operation is achievable using systems like the EEG P-300 paradigm (Kansaku et al., 2010).

\section{INTERACTION WITH PERSONAL COMPUTERS}

Personal computer control of mouse cursors and keyboards is a very useful communication tool for subjects with LIS. One-dimensional (1D) cursor control is achievable using EEG with ERD for operator selection. Decision trees sequentially string selections together to make a final choice (Chatterjee et al., 2007; Kayagil et al., 2009). 2D cursor control can be achieved using techniques like fMRI or EEG. Using four different tasks, $\mathrm{MRI}$ can be used to control both mouse cursors and robotic fingers (Brower, 2005; Coyle et al., 2007; Lee et al., 2009; Sagara et al., 2009). Figure 3 shows a tetraplegic subject using the BrainGate system to operate a computer cursor.

The two most common strategies for obtaining 2D cursor control from an EEG are the P-300 and SSVEP paradigms. P-300 makes use of four movement options that are sequentially highlighted at intermittent stages between movements. Alternatively, using two bands simultaneously, band power is measured from 64 channels over the two hemispheres. Each hemisphere makes opposite signed contributions to each band when controlling direction of cursor movement (Kayagil et al., 2009). This may be achieved using mu and beta waves (Brower, 2005).

Steady-state visually evoked potentials use five EEG electrodes. A single Laplacian referencing channel and four more additional channels that are activated during hand movement. As the systems are hardware and computationally simplistic, effective control is achieved with very little training. This may make future in-home implementation possible. Control of virtual keyboards can be achieved using EEG ERD decision trees or P-300 ERPs. ERD decision trees control $1 \mathrm{D}$ cursor movement while it is moving in a different dimension at a constant rate toward targets on the side of the monitor (Chatterjee et al., 2007; Kayagil et al., 2009).

\section{CONCLUSION}

The present review highlights current research in the neuroengineering field; which has grown rapidly over the last 15 years (Lin et al., 2010). A large number of breakthroughs have been achieved during this time. Disabilities may arise from physical damage to the nervous system or from the genetics of the individual. Disabilities where individuals cannot walk, communicate or perform other desired movements at will, are being addressed. Intelligent wheelchairs and 


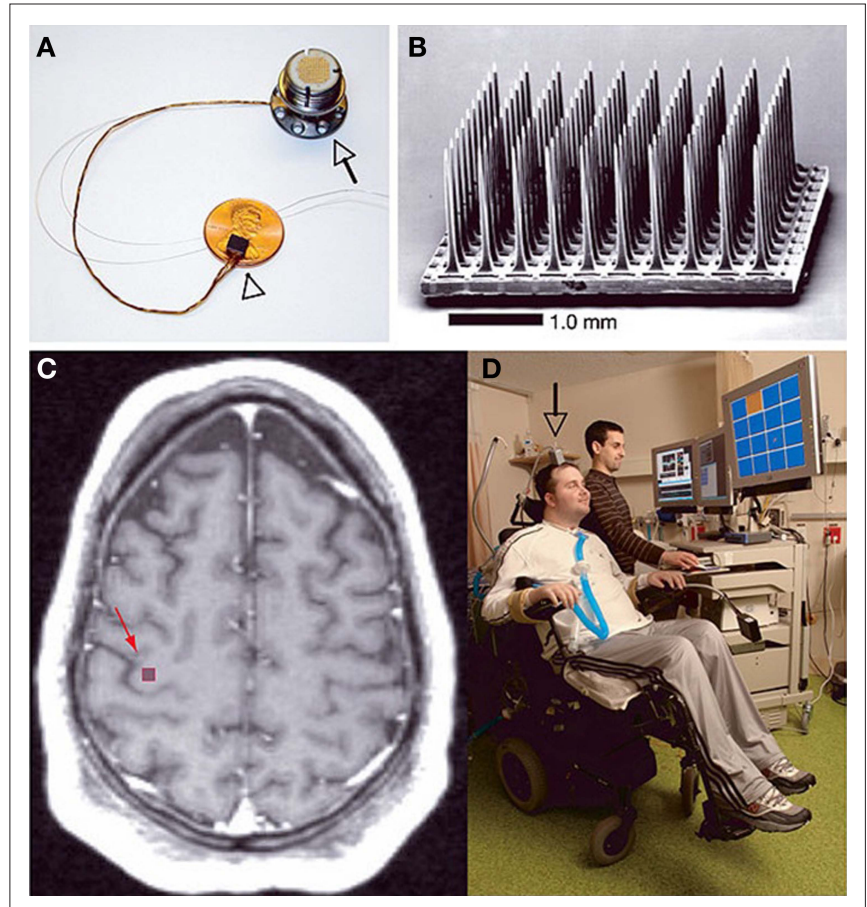

FIGURE 3 |The BrainGate neural interface system created by Cyberkinetics Neurotechnology Systems Incorporated. (A) The BrainGate sensor resting on an American penny, $13 \mathrm{~cm}$ ribbon cable and percutaneous titanium pedestal which is attached to the skull. (B) Scanning electron micrograph of the 100 electrode Utah array. (C) Spin-lattice relaxation time $\left(T_{1}\right)$ weighted magnetic resonance image (MRI) of a tetraplegic subject showing the approximate site of sensor implantation. (D) The first participant of the BrainGate system directing a computer cursor toward the orange square on the PC monitor solely by neural signals. Reprinted with permission from Macmillan Publishers Ltd: Nature 442, 164-171 (Hochberg et al., 2006), copyright 2006.

robotics are being utilized to perform movements directed by the will of individuals. PCs, auditory and visual prosthetics systems are restoring the ability of individuals to communicate and experience sensory sensations, such as rudimentary vision. Neuroengineering will continue to provide new opportunities and restore functioning in people with various disability types. It is very easy to let one's mind wander in regards to potential applications of these devices. The possibilities seem endless.

Potential clinical applications seem to be driving this field's progress. The use of next generation cortical neuroprosthetic devices are bringing the restoration of full-body mobility closer

\section{REFERENCES}

Abu-Nimeh, F. T., Kamboh, A., Aghagolzadeh, M., Jow, U. M., Mason, A., Ghovanloo, M., and Oweiss, K. (2009). "A highly modular, wireless, implantable interface to the cortex," in International IEEE/EMBS Conference on Neural Engineering (NER), Antalya, Turkey, 375-378.

Ahmed, I., Liu, H. Y., Mamiya, P. C., Ponery, A. S., Babu, A. N., Weik, T.,
Schindler, M., and Meiners, S. (2006). Three-dimensional nanofibrillar surfaces covalently modified with tenascin-C-derived peptides enhance neuronal growth in vitro. J. Biomed. Mater. Res. A 76, 851-860.

Avestruz, A. T., Santa, W., Carlson, D., Jensen, R., Stanslaski, S., Helfenstine, A., and Denison, T. (2008). A $5 \mu \mathrm{w} /$ channel spectral analysis IC for chronic bidirectional brain-machine

to being a commercially available reality; for patients that have suffered devastating levels of paralysis from either traumatic or degenerative lesions of the nervous system. This will be made possible by implanting MEAs into multiple cortical areas. Future advances in wearable, whole-body, robotic exoskeletons are likely to become the first reliable, clinically useful and safe neuroprosthetic devices. To make this a reality, teams from all over the world are currently working on the Walk Again Project that aims to restore full body movement in severely paralyzed patients (Nicolelis and Lebedev, 2009).

Brain-machine interface research in conjunction with other methods is adding to the increasing consensus that scattered neural ensembles, opposed to single neurons, constitute the true functional units in the CNS responsible for generating our broad behavioral repertoire (Nicolelis and Lebedev, 2009). The largest hurdle yet to be overcome in this field is the biocompatibility of implanted systems. The use of novel materials, arrangements and shapes are being used to overcome this. Other bottlenecks in the technology include: transmission of recorded data from the subjects to the systems used to interpret it; as well as which techniques should be used for optimal results in the acquisition of data. As more research is carried out, our understanding of the technological limitations involved increases.

Invasive MEAs are promising tools for measuring neural activity as their resolution is far higher than anything else that is currently available. Next generation invasive NISs will require the following characteristics: be fully implantable; automated implantation so that a skilled technician is not required; and lastly device miniaturization to increase mobility. The latter two points are also applicable for non-invasive NISs. Systems such as BrainGate, which consists of 100 electrodes, demonstrate that a quadriplegic subject using a MEA is able to use electronic devices to: open emails; turn lights on or off; operate a television even during a conversation; perform basic actions with a robotic arm; and open and close a prosthetic hand (Brower, 2005; Satava, 2006; Donoghue et al., 2007; Gerven et al., 2009). As possible technological applications expand, the research will undoubtedly follow. This will lead to more opportunities and developments in the field and future avenues of research.

\section{ACKNOWLEDGMENTS}

I thank Dr. P. Soma and Ms. C. O. Govender of the Department of Physiology, University of Pretoria, South Africa, for their valuable comments and help in compiling this document. Financial assistance was provided by the National Research Foundation (NRF) of South Africa.

interfaces. IEEE J. Solid State Circuits 43, 3006-3024.

Babiloni, C., Pizzella, V., Gratta, C. D., Ferretti, A., and Romani, G. L. (2009). Fundamentals of electroencefalography, magnetoencefalography, and functional magnetic resonance imaging. Int. Rev. Neurobiol. 86, 67-80.

Ben-Nissan, B., and Choi, A. H. (2006). Sol-gel production of bioactive nanocoatings for medical applications. Part 1: an introduction. Nanomedicine 1, 311-319.

Bhardwaj, N., and Kundu, S. C. (2010). Electrospinning: a fascinating fiber fabrication technique. Biotechnol. Adv. 28, 325-347.

Birbaumer, N., Murguialday, A. R., and Cohen, L. (2008). Brain-computer interface in paralysis. Curr. Opin. Neurol. 21, 634-638. 
Bossi, S., Kammer, S., Dörge, T., Menciassi, A., Hoffmann, K. P., and Micera, S. (2009).An implantable microactuated intrafascicular electrode for peripheral nerves. IEEE Trans. Biomed. Eng. 56, 2701-2706.

Brower, V. (2005). When mind meets machine. EMBO Rep. 6, 108-110.

Chae, M.S., Liu, W., and Sivaprakasam, M. (2008). Design optimization for integrated neural recording systems. IEEE J. Solid State Circuits 43, 1931-1939.

Chapin, J. K. (2004). Using multi-neuron population recordings for neural prosthetics. Nat. Neurosci. 7, 452-455.

Chatterjee, A., Aggarwal, V., Ramos, A., Acharya, S., and Thakor, N. V. (2007). A brain-computer interface with vibrotactile biofeedback for haptic information. J. Neuroeng. Rehabil. 4,40 .

Chluba, J., Voegel, J. C., Decher, G., Erbacher, P., Schaaf, P., and Ogier, J. (2001). Peptide hormone covalently bound to polyelectrolytes and embedded into multilayer architectures conserving full biological activity. Biomacromolecules 2, 800-805.

Cipriani, C., Antfolk, C., Balkenius, C., Rosén, B., Lundborg, G., Carrozza, M. C., and Sebelius, F. (2009). A novel concept for a prosthetic hand with a bidirectional interface: a feasibility study. IEEE Trans. Biomed. Eng. 56, 2739-2743.

Cottman, E. (2009). Nanotextured Surfaces: New Generation Bioelectronic Interfaces for Nanomedicine (NNIN $R E U)$. Richmond, VA: Virginia Commonwealth University Electrical Engineering Research Accomplishments, 6-7.

Coyle, S.M., Ward, T.E., and Markham, C. M. (2007). Brain-computer interface using a simplified functional nearinfrared spectroscopy system. J Neural Eng. 4, 219-226.

Donoghue, J. P., Nurmikko, A., Black, M., and Hochberg, L. R. (2007). Assistive technology and robotic control using motor cortex ensemble-based neural interface systems in humans with tetraplegia. J. Physiol. 579, 603-611.

Donoho, D. L. (2006). Compressed sensing. IEEE Trans. Inf. Theory 52, 1289-1306.

Eick, S., Wallys, J., Hofmann, B., van Ooyen, A., Schnakenberg, U., Ingebrandt, S., and Offenhausser, A. (2009). Iridium oxide microelectrode arrays for in vitro stimulation of individual rat neurons from dissociated cultures. Front. Neuroeng. 2:16. doi: 10.3389/neuro.16.016.2009.

Finke, A., Lenhardt, A., and Ritter, H. (2009). The MindGame: a P300based brain-computer interface game. Neural Netw. 22, 1329-1333.
Fischer, S. E., Mi, L., Mao, H. Q., and Harden, J. L. (2009). Biofunctional coatings via targeted covalent cross-linking of associating triblock proteins. Biomacromolecules 10 , 2408-2417.

Frewin, C. L., Jaroszeski, M., Weeber, E., Muffly, K. E., Kumar, A., Peters, M., Oliveros, A., and Saddow, S. E. (2009). Atomic force microscopy analysis of central nervous system cell morphology on silicon carbide and diamond substrates. J. Mol. Recogn. 22, 380-388.

Furdea, A., Halder, S., Krusienski, D. J., Bross, D., Nijboer, F., Birbaumer, N., and Kubler, A. (2009). An auditory oddball (P300) spelling system for brain-computer interfaces. Psychophysiology 46, 617-625.

Galán, F., Nuttin, M., Lew, E., Ferrez, P.W., Vanacker, G., Philips, J., and Millán, J. d. R. (2008). A brain-actuated wheelchair: asynchronous and noninvasive brain-computer interfaces for continuous control of robots. Clin. Neurophysiol. 119, 2159-2169.

Garde, K., Keefer, E., Botterman, B., Galvan, P., and Romero, M. I. (2009). Early interfaced neural activity from chronic amputated nerves. Front. Neuroeng. 2:5. doi: 10.3389/ neuro.16.005.2009.

Gawad, S., Giugliano, M., Heuschkel, M., Wessling, B., Markram, H., Schnakenberg, U., Renaud, P., and Morgan, H. (2009). Substrate arrays of iridium oxide microelectrodes for in vitro neuronal interfacing. Front. Neuroeng. 2:1. doi: 10.3389/ neuro.16.001.2009.

Geddes, L. A., and Roeder, R. (2003). Criteria for the selection of materials for implanted electrodes. Ann. Biomed. Eng. 31, 879-890.

Gerven, M. V., Farquhar, J., Schaefer, R., Vlek, R., Geuze, J., Nijholt,A., Ramsey, N., Haselager, P., Vuurpijl, L., Gielen, S., and Desain, P. (2009). The braincomputer interface cycle. J. Neural Eng. 6, 041001.

Gupta, R., and Kumar, A. (2008). Bioactive materials for biomedical applications using sol-gel technology. Biomed. Mater. 3. doi: 10.1088/17486041/3/3/034005.

Hetke, J. F., Lund, J. L., Najafi, K., Wise, K. D., and Anderson, D. J. (1994). Silicon ribbon cables for chronically implantable microelectrode arrays. IEEE Trans. Biomed. Eng. 41, 314-321.

Hochberg, L. R., Serruya, M. D., Friehs, G. M., Mukand, J.A., Saleh, M., Caplan, A. H., Branner, A., Chen, D., Penn, R. D., and Donoghue, J. P. (2006). Neuronal ensemble control of prosthetic devices by a human with tetraplegia. Nature 442, 164-171.
Horch, K. W., and Dhillon, G. S. (2004). Neuroprosthetics: Theory and Practice. Series on Bioengineering and Biomedical Engineering. Singapore: World Scientific Publishing Co. Pte. Ltd.

Huerta, P. T., and Volpe, B. T. (2009). Transcranial magnetic stimulation, synaptic plasticity and network oscillations. J. Neuroeng. Rehabil. 6, 7.

Jakubek, L. M., Marangoudakis, S., Raingo, J., Liu, X., Lipscombe, D., and Hurt, R. H. (2009). The inhibition of neuronal calcium ion channels by trace levels of yttrium released from carbon nanotubes. Biomaterials 30, 6351-6357.

James, C. D., Spence, A. J., Dowell-Mesfin, N. M., Hussain, R. J., Smith, K. L., Craighead, H. G., Isaacson, M. S., Shain, W., and Turner, J. N. (2004). Extracellular recordings from patterned neuronal networks using planar microelectrode arrays. IEEE Trans. Biomed. Eng. 51, 1640-1648.

Ju, J. S., Shin, Y., and Kim, E. Y. (2009). Vision based interface system for hands free control of an intelligent wheelchair. J. Neuroeng. Rehabil. 6, 33.

Kansaku, K., Hata, N., and Takano, K. (2010). My thoughts through a robot's eyes: an augmented reality-brainmachine interface. Neurosci. Res. 66, 219-222.

Kayagil, T. A., Bai, O., Henriquez, C. S. Lin, P., Furlani, S. J., Vorbach, S., and Hallett, M. (2009). A binary method for simple and accurate two-dimensional cursor control from EEG with minimal subject training. J. Neuroeng. Rehabil. 6, 14.

Koh, H. S., Yong, T., Chan, C. K., and Ramakrishna, S. (2008). Enhancement of neurite outgrowth using nanostructured scaffolds coupled with laminin. Biomaterials 29, 3574-3582.

Konrad, P., and Shanks, T. (2010) Implantable brain computer interface: challenges to neurotechnology translation. Neurobiol. Dis. 38, 369-375.

Leach, J. B., Achyuta, A. K., and Murthy, S. K. (2010). Bridging the divide between neuroprosthetic design, tissue engineering and neurobiology. Front. Neuroeng. 2:18. doi: 10.3389/ neuro.16.018.2009.

Lebedev, M. A., and Nicolelis, M. A. L. (2006). Brain-machine interfaces: past, present and future. Trends Neurosci. 29, 536-546.

Lee, J. H., Ryu, J., Jolesz, F. A., Cho, Z. H., and Yoo, S. S. (2009). Brain-machine interface via real-time fMRI: preliminary study on thought-controlled robotic arm. Neurosci. Lett. 450, 1-6.

Lee, W., and Parpura, V. (2009). Wiring neurons with carbon nanotubes. Front. Neuroeng. 2:8. doi: 10.3389/ neuro.16.008.2009.
Lin, C. T., Ko, L. W., Chang, M. H., Duann, J. R., Chen, J. Y., Su, T. P., and Jung, T. P. (2010). Review of wireless and wearable electroencephalogram systems and brain-computer interfaces - a mini-review. Gerontology 56, 112-119.

Massobrio, G., Massobrio, P., and Martinoia, S. (2008). Modeling the neuron-carbon nanotube-ISFET junction to investigate the electrophysiological neuronal activity. Nano Lett. 8, 4433-4440.

McCarthy, P. T., Madangopal, R., Otto, K. J., and Rao, M. P. (2009). Titaniumbased multi-channel, micro-electrode array for recording neural signals. Conf. Proc. IEEE Eng. Med. Biol. Soc. 2009, 2062-2065.

Memarian, N., Venetsanopoulos, A. N., and Chau, T. (2009). Infrared thermography as an access pathway for individuals with severe motor impairments. J. Neuroeng. Rehabil. 6, 11.

Micera, S., Navarro, X., Carpaneto, J., Citi, L., Tonet, O., Rossini, P. M., Carrozza, M. C., Hoffmann, K. P., Vivó, M., Yoshida, K., and Dario, P. (2008). On the use of longitudinal intrafascicular peripheral interfaces for the control of cybernetic hand prostheses in amputees. IEEE Trans. Neural Syst. Rehabil. Eng. 16, 453-472.

Morillas, C., Romero, S., Martínez, A., Pelayo, F., Reyneri, L., Bongard, M., and Fernández, E. (2007). A neuroengineering suite of computational tools for visual prostheses. Neurocomputing 70, 2817-2827.

Moxon, K. A., Hallman, S., Aslani, A., Kalkhoran, N. M., and Lelkes, P. I. (2007). Bioactive properties of nanostructured porous silicon for enhancing electrode to neuron interfaces. J. Biomater. Sci. Polym. Ed. 18, 1263-1281.

Moxon, K.A., Kalkhoran, N. M., Markert, M., Sambito, M.A., McKenzie, J.L., and Webster, J. T. (2004). Nanostructured surface modification of ceramic-based microelectrodes to enhance biocompatibility for a direct brain-machine interface.IEEE Trans. Biomed. Eng. 51, 881-889.

Muller-Putz, G. R., Scherer, R., Pfurtscheller, G., Neuper, C., and Rupp, R. (2009). Non-invasive control of neuroprostheses for the upper extremity: temporal coding of brain patterns. Conf. Proc. IEEE Eng. Med. Biol. Soc. 2009, 3353-3356.

Navarro, X., Krueger, T. B., Lago, N., Micera, S., Stieglitz, T., and Dario, P. (2005). A critical review of interfaces with the peripheral nervous system for the control of neuroprostheses and hybrid bionic systems. J. Peripher. Nerv. Syst. 10, 229-258. 
Neuper, C., Scherer, R., Wriessnegger, S., and Pfurtscheller, G. (2009). Motor imagery and action observation: modulation of sensorimotor brain rhythms during mental control of a brain-computer interface. Clin. Neurophysiol. 120, 239-247.

Nicolelis, M. A. (2001). Actions from thoughts. Nature 409, 403-407.

Nicolelis, M. A. L., and Lebedev, M. A. (2009). Principles of neural ensemble physiology underlying the operation of brain-machine interfaces. Nat. Rev Neurosci. 10, 530-540.

Nijboer, F., Furdea, A., Gunst, I., Mellinger, J., McFarland, D. J., Birbaumer, N., and Kubler, A. (2008). An auditory braincomputer interface (BCI). J. Neurosci. Methods 167, 43-50.

Pancrazio, J. J., and Peckham, P. H. (2009). Neuroprosthetic devices: how far are we from recovering movement in paralyzed patients? Expert Rev. Neurother. 9, 427-430.

Panetsos, F., Diaz-De Cerio, E., SanchezJimenez, A., and Herrera-Rincon, C. (2009). "Thalamic visual neuroprostheses: comparison of visual percepts generated by natural stimulation of the eye and electrical stimulation of the thalamus," in International IEEE/EMBS Conference on Neural Engineering (NER), Antalya, Turkey, 56-59.

Patrick, E., Sankar, V., Rowe, W., Yen, S. F., Sanchez, J. C., and Nishida, T. (2008). Flexible polymer substrate and tungsten microelectrode array for an implantable neural recording system. Conf. Proc. IEEE Eng. Med. Biol. Soc. 2008, 3158-3161.

Quiroga, R. Q., Reddy, L., Koch, C., and Fried, I. (2007). Decoding visual inputs from multiple neurons in the human temporal lobe. J. Neurophysiol. 98, 1997-2007.

Rao, S. S., and Winter, J. O. (2009). Adhesion molecule-modified biomaterials for neural tissue engineering. Front. Neuroeng. 2:6. doi: 10.3389/ neuro.16.006.2009.

Rizk, M., Bossetti, C. A., Jochum, T. A., Callender, S. H., Nicolelis, M. A., Turner, D. A., and Wolf, P. D. (2009). A fully implantable 96-channel neural data acquisition system. J Neural Eng. 6, 026002 .

Rondoni, D., and Hoekstra, J. (2005). "Toward models for CNT devices," in Proceedings of 16th Annual Workshop on Circuits, Systems and Signal Processing. Utrecht: Dutch Technology Foundation, 272-278.

Rossini, P. M., Rossi, S., Babiloni, C., and Polich, J. (2007). Clinical neurophysiology of aging brain: from normal aging to neurodegeneration. Prog. Neurobiol. 83, 375-400.

Rousche, P. J., and Normann, R. A. (1998). Chronic recording capability of the Utah intracortical electrode array in cat sensory cortex. J. Neurosci. Methods 82, 1-15.

Ryu, S.I., and Shenoy, K.V. (2009).Human cortical prostheses: lost in translation? Neurosurg. Focus 27, E5.

Sagara, K., Kido, K., and Ozawa, K. (2009). Portable single-channel NIRS-based BMI system for motor disabilities' communication tools. Conf. Proc. IEEE Eng. Med. Biol. Soc. 2009, 602-605.

Satava, R. M. (2006). Surgeon responsibility in the era of "outrageous science". Surg. Endosc. 20, 1797-1801.

Shoval, A., Adams, C., David-Pur, M., Shein, M., Hanein, Y., and Sernagor, E. (2009). Carbon nanotube electrodes for effective interfacing with retinal tissue. Front. Neuroeng. 2:4. doi: 10.3389/ neuro.16.004.2009

Smith, S. L., Judy, J. W., and Otis, T. S. (2004). An ultra small array of electrodes for stimulating multiple inputs into a single neuron. J. Neurosci. Methods. 133, 109-114.

Sodagar, A.M., Perlin, G. E., Yao, Y., Najafi, K., and Wise, K.D. (2009). An implantable 64-channel wireless microsystem for single-unit neural recording. IEEE J. Solid State Circuits 44, 2591-2604.

Song, Y. K., Patterson, W. R., Bull, C. W., Borton, D. A., Li, Y., Nurmikko, A. V., Simeral, J. D., and Donoghue, J. P. (2007). A brain implantable microsystem with hybrid RF/IR telemetry for advanced neuroengineering applications. Conf. Proc. IEEE Eng. Med. Biol. Soc. 2007, 445-448.

Soraghan, C., Matthews, F., Markham, C., Pearlmutter, B. A., O'Neill, R., and Ward, T. E. (2008). A 12-channel, real-time near-infrared spectroscopy instrument for brain-computer interface applications. Conf. Proc. IEEE Eng. Med. Biol. Soc. 2008, 5648-5651.

Sorkin, R., Gabay, T., Blinder, P., Baranes, D., Ben-Jacob, E., and Hanein, Y. (2006). Compact self-wiring in cultured neural networks. J. Neural Eng. 3, 95-101.

Straley, K. S., and Heilshorn, S. C. (2009). Design and adsorption of modular engineered proteins to prepare customized, neuron-compatible coatings. Front. Neuroeng. 2:9. doi: 10.3389/ neuro.16.009.2009.

Tai, K., and Chau, T. (2009). Single-trial classification of NIRS signals during emotional induction tasks: towards a corporeal machine interface. $J$. Neuroeng. Rehabil. 6, 39.

Thakor, N. V. (2008). Neuroengineering: building interfaces from neurons to brain. Conf. Proc. IEEE Eng. Med. Biol. Soc. 2008, 1602-1603.

Tsubone, T., Muroga, T., and Wada, Y (2007). Application to robot control using brain function measurement by near-infrared spectroscopy. Conf. Proc. IEEE Eng. Med. Biol. Soc. 2007 , 5342-5345.

Utsugi, K., Obata, A., Sato, H., Katsura T., Sagara, K., Maki, A., and Koizumi, H. (2007). Development of an optical brain-machine interface. Conf. Proc. IEEE Eng. Med. Biol. Soc. 2007, 5338-5341.

Ward, M. P., Rajdev, P., Ellison, C., and Irazoqui, P. P. (2009). Toward a comparison of microelectrodes for acute and chronic recordings. Brain Res. 1282, 183-200.

Wei, X. F., and Grill, W.M. (2009). Analysis of high-perimeter planar electrodes for efficient neural stimulation. Front. Neuroeng. 2:15. doi: 10.3389/ neuro.16.015.2009.

Wildöer, J. W. G., Venema, L. C., Rinzler, A. G., Smalley, R. E., and Dekker, C. (1998). Electronic structure of atomically resolved carbon nanotubes. Nature 391, 59-62.

Wilks, S. J., Richardson-Burns, S. M., Hendricks, J. L., Martin, D. C., and Otto, K. J. (2009). Poly(3, 4-ethylenedioxythiophene) as a micro-neural interface material for electrostimulation. Front. Neuroeng. 2:7. doi: 10.3389/ neuro.16.007.2009.

Wilson, J. A., and Williams, J. C. (2009). Massively parallel signal processing using the graphics processing unit for real-time brain-computer interface feature extraction. Front. Neuroeng. 2:11. doi: 10.3389/ neuro.16.011.2009.

Yaeli, S., Binyamin, E., and Shoham, S. (2009). Form-function relations in cone-tipped stimulating microelectrodes. Front. Neuroeng. 2, 13. doi: 10.3389/neuro.16.013.2009.

Zeng, F. G., and Micera, S. (2007). Guest editorial: sense and sensibility in neuroengineering. IEEE Trans. Biomed. Eng. 54, 965-968.

Zhong, Y., and Bellamkonda, R.V. (2008). Biomaterials for the central nervous system. J. R. Soc. Interface 5, 957-975.

Zhu, H., Ji, J., Tan, Q., Barbosa, M. A., and Shen, J. (2003). Surface engineering of poly(DL-lactide) via electrostatic self-assembly of extracellular matrixlike molecules. Biomacromolecules 4, 378-386.

Conflict of Interest Statement: The author declares that the research was conducted in the absence of any commercial or financial relationships that could be construed as a potential conflict of interest.

Received: 20 June 2010; accepted: 22 September 2010; published online: 15 October 2010

Citation: Rothschild RM (2010)

Neuroengineering tools/applications for bidirectional interfaces, brain-computer interfaces, and neuroprosthetic implants a review of recent progress. Front. Neuroeng. 3:112. doi: 10.3389/fneng.2010.00112

Copyright $\odot 2010$ Rothschild. This is an open-access article subject to an exclusive license agreement between the authors and the Frontiers Research Foundation, which permits unrestricted use, distribution, and reproduction in any medium, provided the original authors and source are credited. 